\title{
Oxidized low-density lipoprotein decreases VEGFR2 expression in HUVECs and impairs angiogenesis
}

\author{
MIN ZHANG and LI JIANG \\ Division of Cardiology, Shanghai Tongren Hospital, School of Medicine, Shanghai Jiao Tong University, \\ Shanghai 200336, P.R. China
}

Received June 27, 2015; Accepted September 6, 2016

DOI: $10.3892 /$ etm.2016.3823

\begin{abstract}
Atherosclerosis (AS), which is triggered by endothelial cell injury, evolves into a chronic inflammatory disease. Oxidized low-density lipoprotein (ox-LDL) is an important risk factor for the development of atherosclerosis; ox-LDL induces atherosclerotic plaque formation via scavenging receptors. The present study used ox-LDL-treated human umbilical vein endothelial cells (HUVECs) to investigate the effect of ox-LDL on angiogenesis. ox-LDL decreased HUVEC proliferation by MTT, induced apoptosis by Annexin V-fluorescein isothiocyanate (FITC) staining and markedly suppressed HUVEC tube formation by the Matrigel assay in a dose-dependent manner. Angiogenesis has been correlated with monocyte invasion, plaque instability and atherosclerotic lesion formation. In addition, ox-LDL induced the overproduction of reactive oxygen species using DCFH-DA staining and increased caspase-3 activity. Vascular endothelial growth factor receptor 2 (VEGFR2) were detected by quantitative polymerase chain reaction and western blot analysis and has previously been observed to have a key role in angiogenesis. Furthermore, the present study demonstrated that the abundance of VEGFR2 was decreased in ox-LDL-treated HUVECs. These results suggested that ox-LDL impairs angiogenesis via VEGFR2 degradation, thus suggesting that VEGFR2 may be involved in adaptation to oxidative stress and AS.
\end{abstract}

\section{Introduction}

Atherosclerosis (AS) occurs as a result of endothelium injury, and leads to clogged arteries, resulting in heart attacks and strokes (1). It has recently been demonstrated that oxidized low-density lipoprotein (ox-LDL) has a key role in early

Correspondence to: Dr Li Jiang, Division of Cardiology, Shanghai Tongren Hospital, School of Medicine, Shanghai Jiao Tong University, 1111 Xianxia Road, Shanghai 200336, P.R. China E-mail: zm19821982@hotmail.com

Key words: atherosclerosis, oxidized low-density lipoprotein, human umbilical vein endothelial cells, vascular endothelial growth factor receptor 2 , angiogenesis inflammatory processes and may induce atherosclerotic lesions (2). In the process of atherosclerotic lesion formation, ox-LDL promotes the initiation of monocyte invasion and is taken up by monocytes/macrophages and endothelial cells via scavenger receptors on the cell surface (2). The subsequent accumulation of cholesterol in macrophages and foam cells is an indicator of atherosclerotic lesion formation. In addition, ox-LDL increases the permeability of endothelial cells and promotes their dysfunction (2). Previous studies have demonstrated that ox-LDL may significantly delay endothelium wound healing, and that the expression of numerous key genes in endothelial cells was changed following ox-LDL treatment, thus altering the function of the endothelium $(3,4)$.

At the molecular level, ox-LDL has been demonstrated to promote the expression of adhesion molecules, heat shock proteins and coagulation proteins; to suppress the production of endothelium-derived nitric oxide (NO) and prostacyclin; and to induce the expression of various proinflammatory cytokines and growth factors in vascular cells (5-9). Therefore, inhibiting ox-LDL-induced vascular endothelial cell injury may be a potential therapeutic strategy for AS.

Previous studies have demonstrated that endothelial dysfunction and inflammation are precursors of AS $(10,11)$. Numerous pathological conditions, including dyslipidemia, hypertension and hyperglycemia, have been associated with the overexpression of reactive oxygen species (ROS), which may stimulate endothelial cells and induce inflammatory responses $(12,13)$. The necrosis of injured endothelial cells may result in the release of various pro-inflammatory factors, including intercellular adhesion molecule-1 and vascular cell adhesion molecule-1; these pro-inflammatory factors induce the formation of atherosclerotic plaques (14). Therefore, anti-inflammatory responses may be important for the prevention of AS.

Various growth factors and cytokines are involved in angiogenesis, including vascular endothelial growth factor (VEGF). VEGF binds to VEGF receptors (VEGFR) on the surface of cells, which induces the phosphorylation of downstream signaling molecules, including mitogen-activated protein kinase, focal adhesion kinase, Src kinase and signal transducer (15). The main subtypes of VEGFRs are VEGFRs 1-3, which are predominantly located on the surface of healthy tissue cells. However, VEGFRs have been observed to be upregulated during embryonic and tumor angiogenesis. VEGFR1 is a decoy receptor that has a low tyrosine kinase 
activity (16). Conversely, previous studies have suggested that VEGFR2 has a critical role in cell proliferation, migration and tube formation, leading to angiogenesis $(17,18)$.

However, to the best of our knowledge, the cytoprotective effect of VEGFR2 on oxLDL-induced human umbilical vein endothelial cell (HUVEC) injury has yet to be investigated clearly. The present study aimed to investigate the effect of ox-LDL on angiogenesis by exposing HUVECs to ox-LDL and performing endothelial proliferation and angiogenesis assays. In addition, the role of VEGFR2 in AS was determined.

\section{Materials and methods}

Chemicals, antibodies and reagents. LDL was purchased from R\&D Systems GmbH (Wiesbaden, Germany). Calcein-AM was purchased from Dojindo Molecular Technologies, Inc. (Shanghai, China). Rabbit anti-VEGFR2 polyclonal antibody was obtained from Abcam (1:100; ab39256; Cambridge, UK). Phycoerythrin (PE)-conjugated mouse anti-VEGFR2 monoclonal antibody (1:500; FAB357P; clone 12G5) and purified mouse immunoglobulin (Ig)G $(1: 500 ; 550874)$ were purchased from BD Biosciences (Heidelberg, Germany). Recombinant human VEGF165 (11066-HNAB-500) was obtained from Sino Biological, Inc. (Beijing, China). Rabbit anti- $\beta$-actin (1:500; ab16039, Abcam) and rabbit anti-human glyceraldehyde 3-phosphate dehydrogenase (GAPDH; 1:500; SAB2108266) polyclonal antibodies were obtained from Sigma-Aldrich Chemie GmbH (Deisenhofen, Germany).

Cell culture and LDL treatment. In total $2 \times 10^{5}$ HUVECs (AllCells, LLC, Shanghai, China) were cultured for 3-5 passages in Dulbecco's modified Eagle's medium (DMEM; PromoCell GmbH, Heidelberg, Germany) supplemented with $10 \%$ fetal bovine serum (unless otherwise specified), $0.1 \mathrm{ng} / \mathrm{ml}$ human epidermal growth factor, $1 \mathrm{ng} / \mathrm{ml}$ basic fibroblast growth factor (bFGF), $90 \mathrm{ng} / \mathrm{ml}$ heparin and $1 \mathrm{ng} / \mathrm{ml}$ hydrocortisone (all purchased from Sigma-Aldrich Chemie $\mathrm{GmbH}$ ). Cells were incubated at $37^{\circ} \mathrm{C}$ for $24 \mathrm{~h}$ in a humidified $5 \% \quad \mathrm{CO}_{2}$ incubator at $21 \% \mathrm{O}_{2}$. Ox-LDL was prepared by exposure of native LDL to $5 \mu \mathrm{M}$ copper sulphate (Sigma-Aldrich Chemie $\mathrm{GmbH}$ ) at $37^{\circ} \mathrm{C}$ for $3 \mathrm{~h}$. The reaction was stopped by the addition of $0.25 \mathrm{mM}$ ethylenediaminetetraacetic acid, as described previously (19). Ox-LDL $(0-100 \mu \mathrm{g} / \mathrm{ml})$ was added to the cells alone or in combination with each other at $37^{\circ} \mathrm{C}$ for $24 \mathrm{~h}$.

Cell proliferation assay. The MTT assay (Sigma-Aldrich Chemie $\mathrm{GmbH}$ ) was used to assess the proliferation of HUVECs, according to the manufacturer's protocol. Briefly, HUVECs (1x10 4 cells/well) were plated onto 96-well plates and treated with ox-LDL at $37^{\circ} \mathrm{C}$ for $24 \mathrm{~h}$, after which MTT (20 $\mu \mathrm{l}, 5 \mathrm{~g} / \mathrm{l})$ was added to media and incubated for $4 \mathrm{~h}$. Subsequently, the supernatant was removed by centrifugation at $1000 \mathrm{xg}$ for $10 \mathrm{~min}$ at $4^{\circ} \mathrm{C}$, and dimethylsulfoxide was added to solubilize the formazan crystals. Absorbance was measured at $560 \mathrm{~nm}$ using an ELISA plate reader.

Cell apoptosis assay. The apoptosis of HUVECs induced by ox-LDL starvation was detected by Annexin V-fluorescein isothiocyanate (FITC) staining assays (Nanjing KeyGen Biotech, Co., Ltd., Nanjing, China). Briefly, 1x10 ${ }^{4}$ HUVECs were cultured with DMEM supplemented with $10 \mathrm{ng} / \mathrm{ml}$ VEGF and in the presence or absence of ox-LDL for $48 \mathrm{~h}$. The cells were incubated with ox-LDL $(0-100 \mu \mathrm{g} / \mathrm{ml})$, VEGF $(10 \mathrm{ng} / \mathrm{ml})$ or both for $48 \mathrm{~h}$. HUVECs were then collected and washed with phosphate-buffered saline (PBS) three times, after which Annexin V-FITC and propidium iodide were added to the washed cells $\left(10^{6}\right.$ cell $\left.\mathrm{s} / \mathrm{ml}\right)$ for $15 \mathrm{~min}$ at room temperature in the dark. Subsequently, fluorescence-activated cell sorting buffer was added and the cells were immediately analyzed by flow cytometry.

Endothelial cell wound healing assay. HUVECs $\left(1 \times 10^{5}\right.$ cells/well) were seeded into 12 -well plates and were scratched with pipette tips, followed by treatment with $100 \mu \mathrm{g} / \mathrm{ml}$ ox-LDL. Migration of cells into the wound was then observed at $37^{\circ} \mathrm{C}$ for $24 \mathrm{~h}$. The migrated cells were visualized and imaged under a microscope at various time points. Experiments were performed in triplicate at least three times.

Tube formation assay. HUVECs $\left(2 \times 10^{4}\right)$ were seeded into Matrigel-coated wells of a 96-well plate. The cells were incubated with ox-LDL $(0-100 \mu \mathrm{g} / \mathrm{ml})$ and/or VEGF $(10 \mathrm{ng} / \mathrm{ml})$ for $24 \mathrm{~h}$, during which cells were maintained in an incubator at $37^{\circ} \mathrm{C}$ containing $21 \% \mathrm{O}_{2}$. Images were captured at low magnification (magnification, x5) under a microscope and tubes were counted. Only perfectly continuous tubes between two branching points were included. For each condition, three independent experiments were performed, of which mean tube numbers are presented.

Intracellular ROS production. HUVECs $\left(2 \times 10^{5}\right.$ cells/well) were seeded into a 6 -well plate and treated with ox-LDL $(0-100 \mu \mathrm{g} / \mathrm{ml})$ for $24 \mathrm{~h}$. The dichlorofluorescein diacetate (DCFH-DA) assay (Sigma-Aldrich Chemie $\mathrm{GmbH}$ ) was used to measure the intracellular levels of ROS. Briefly, following treatment, the cells were incubated with $10 \mu \mathrm{M}$ DCFH-DA for $30 \mathrm{~min}$ at $37^{\circ} \mathrm{C}$. Flow cytometry was used to detect the fluorescence intensity.

Measurement of caspase-3 activity. The activity of caspase-3 was measured using a Caspase-3 Cellular Activity Assay kit (Nanjing KeyGen Biotech, Co., Ltd.), according to the manufacturer's protocol. Briefly, $1 \times 10^{4}$ HUVECs were removed from culture dishes, washed twice with PBS and centrifuged at $10,000 \mathrm{x} \mathrm{g}$ for $1 \mathrm{~min}$ at $4^{\circ} \mathrm{C}$. Cell pellets were then treated for $30 \mathrm{~min}$ with ice-cold lysis buffer provided by the manufacturer of the kit. Cell suspensions were then centrifuged at $10,000 \mathrm{x}$ for $1 \mathrm{~min}$ at $4^{\circ} \mathrm{C}$ and the supernatants were transferred to a clear tube. To each tube, $2 \mathrm{X}$ reaction buffer and specific substrate for caspase- 3 were added, and the tubes were incubated at $37^{\circ} \mathrm{C}$ for $4 \mathrm{~h}$. Following incubation, caspase- 3 activity was measured at $405 \mathrm{~nm}$ using a micrometer plate reader.

Reverse transcription-quantitative polymerase chain reaction $(R T-q P C R)$. A total of $1 \times 10^{4}$ HUVECs were treated with various concentrations of ox-LDL $(0-100 \mu \mathrm{g} / \mathrm{ml})$ for $24 \mathrm{~h}$ or $100 \mu \mathrm{g} / \mathrm{ml}$ ox-LDL for 24-72 h, after which total RNA was extracted from 
HUVECs using the RNeasy Midi kit (Qiagen GmbH, Hilden, Germany), according to manufacturer's protocol. Total RNA $(1 \mu \mathrm{l})$ was reverse transcribed into cDNA using iScript cDNA synthesis kit (Bio-Rad Laboratories, Inc., Hercules, CA, USA). qPCR was performed using Power SYBR ${ }^{\circledR}$ Green PCR Master Mix (Eurogentec, Verviers, Belgium) on the StepOnePlus ${ }^{\mathrm{TM}}$ Real-Time PCR System (Applied Biosystems; Thermo Fisher Scientific, Inc., Waltham, MA, USA). The following primers were used: VEGFR2 forward, 5'-CTCTTGGCCGTGGTGCCT TTG and reverse, 3'-GTGTGTTGCTCCTTCTTTCAAC; and GAPDH forward, 5'-CATCTTCCAGGAGCGAGATCC and reverse, 3'-GGTGCAGGTGGCATTGCTGATG. GAPDH was used as housekeeping gene. The PCR cycling conditions were as follows: Denaturation at $95^{\circ} \mathrm{C}$ for $10 \mathrm{~min}$, followed by 40 cycles at $95^{\circ} \mathrm{C}$ for $15 \mathrm{sec}$ and $60^{\circ} \mathrm{C}$ for $1 \mathrm{~min}$. All samples and standards were conducted in triplicate. The relative mRNA expression was determined using the $2 \Delta \Delta c_{q}$ method. A negative control without RT enzyme and an RT-minus control (without reverse transcriptase added to the cDNA synthesis reaction) were used.

Western blot analysis. A total of $2 \times 10^{5}$ HUVECs were treated with ox-LDL $(0-100 \mu \mathrm{g} / \mathrm{ml})$ at $37^{\circ} \mathrm{C}$ for $72 \mathrm{~h}$, after which HUVECs were washed with PBS and lysed using radioimmunoprecipitation assay (Thermo Fisher Scientific, Inc.) lysis buffer. Cell lysates were centrifuged at $10,000 \times \mathrm{x} g$ for $10 \mathrm{~min}$ at $4^{\circ} \mathrm{C}$, after which protein concentrations were determined using a Pierce BCA Protein Assay kit (23225; Sigma-Aldrich Chemie $\mathrm{GmbH}$ ). Total lysate proteins $(40 \mu \mathrm{g})$ were resuspended in loading buffer and separated by $10 \%$ SDS-PAGE, followed by transfer onto a polyvinylidene difluoride membrane. For detection of VEGFR2, the membranes were incubated overnight at $4^{\circ} \mathrm{C}$ with rabbit anti-VEGFR 2 and rabbit anti- $\beta$-actin polyclonal antibodies (1:400). After washing three times with Tris-buffered saline containing Tween-20, the membranes were blocked with $5 \%$ bovine serum albumin for $1 \mathrm{~h}$ at room temperature and incubated with peroxidase-conjugated goat anti-rabbit $\operatorname{IgG}$ $(1: 2,000$; Abcam) for $1 \mathrm{~h}$ and then detected by incubation with chromomeric substrate, 3, 3'-diaminobenzidine.

Statistical analysis. Data are expressed as the mean \pm standard deviation. Comparisons among groups were performed by one-way analysis of variance followed by Tukey's post-hoc test. Comparisons between two groups were performed by two-tailed unpaired t-tests. Statistical analysis was performed using SPSS 10.0 software for Windows (SPSS, Inc., Chicago, IL, USA). $\mathrm{P}<0.05$ was considered to indicate a statistically significant difference.

\section{Results}

$O x-L D L$ reduces cell viability in a dose-dependent manner. MTT assays were used to evaluate the effect of ox-LDL on the viability of HUVECs. HUVECs were cultured in growth factor-deprived DMEM containing ox-LDL $(0-100 \mu \mathrm{g} / \mathrm{ml})$ for $24 \mathrm{~h}$. Fig. 1 shows that HUVEC proliferation was decreased following treatment with ox-LDL in a dose-dependent manner; the proliferation of HUVECs was significantly decreased following treatment with $100 \mu \mathrm{g} / \mathrm{ml}$ ox-LDL $(\mathrm{P}<0.05)$. These results suggest that ox-LDL reduces the viability of HUVECs.

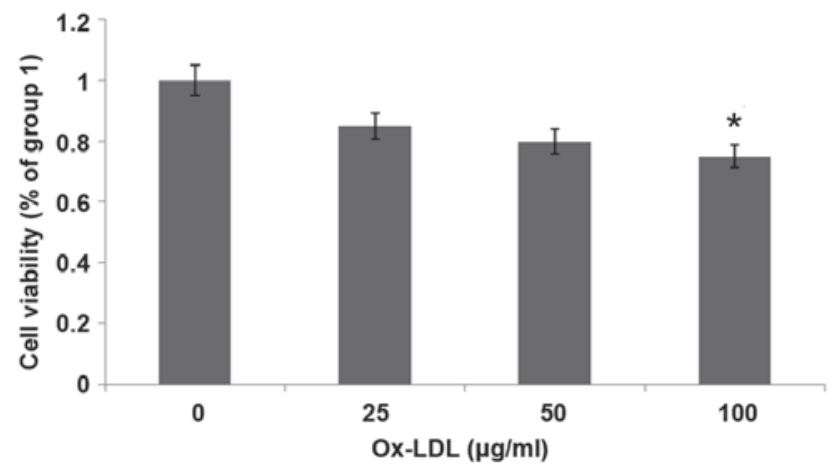

Figure 1. Effect of ox-LDL on the proliferation of HUVECs compared to group 1. HUVECs were treated with $0,25,50$ or $100 \mu \mathrm{g} / \mathrm{ml}$ ox-LDL for $24 \mathrm{~h}$, after which cell proliferation was assessed using MTT assays. Ox-LDL decreased the proliferation of HUVECs in a dose-dependent manner. Data are expressed as the mean \pm standard deviation. ${ }^{*} \mathrm{P}<0.05$, vs. the control $(0 \mu \mathrm{g} / \mathrm{ml})$. Ox-LDL, oxidized low-density lipoprotein; HUVECs, human umbilical vein endothelial cells.

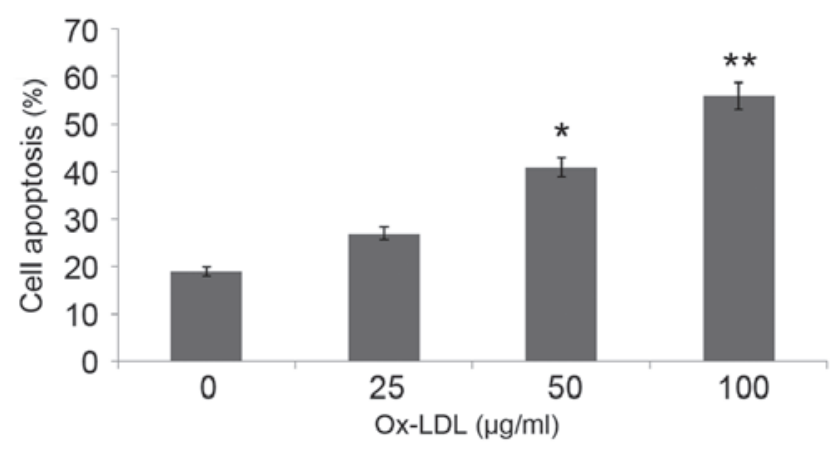

Figure 2. Effect of ox-LDL on the apoptosis of HUVECs. HUVECs were treated with $0,25,50$ or $100 \mu \mathrm{g} / \mathrm{ml}$ ox-LDL for $48 \mathrm{~h}$, after which the percentage of cell apoptosis was detected by flow cytometry. Ox-LDL induced the apoptosis of HUVECs in a dose-dependent manner. Data are expressed as the mean \pm standard deviation. ${ }^{*} \mathrm{P}<0.05,{ }^{* *} \mathrm{P}<0.01$, vs. the control $(0 \mu \mathrm{g} / \mathrm{ml})$. Ox-LDL, oxidized low-density lipoprotein; HUVECs, human umbilical vein endothelial cells.

Ox-LDL induces HUVEC apoptosis in a dose-dependent manner. In order to investigate the effect of ox-LDL on HUVEC apoptosis, serum deprivation-induced apoptosis of HUVECs was assessed by flow cytometry. Serum deprivation induced apoptosis of $\sim 19 \%$ of HUVECs, which was significantly increased to $56 \%$ following treatment with $100 \mu \mathrm{g} / \mathrm{ml}$ ox-LDL for $48 \mathrm{~h}(\mathrm{P}<0.01$; Fig. 2). These results suggest that ox-LDL induces the apoptosis of HUVECs.

Ox-LDL dose-dependently decreases HUVEC migration. Cell migration is an essential process in angiogenesis. The present study performed wound healing assays to investigate the effects of ox-LDL on the migration of HUVECs. ox-LDL $(100 \mu \mathrm{g} / \mathrm{ml})$ markedly inhibited the migration of HUVECs into the wound area (Fig. 3). This effect was significant at 6 , 12 and $24 \mathrm{~h}$, as compared with the control $(\mathrm{P}<0.05$; Fig. 3$)$.

Ox-LDL dose-dependently inhibits angiogenesis. In order to elucidate the potential underlying mechanisms of the effects of ox-LDL on angiogenesis, the tube-forming ability of HUVECs was assessed in vitro. HUVECs were cultured 

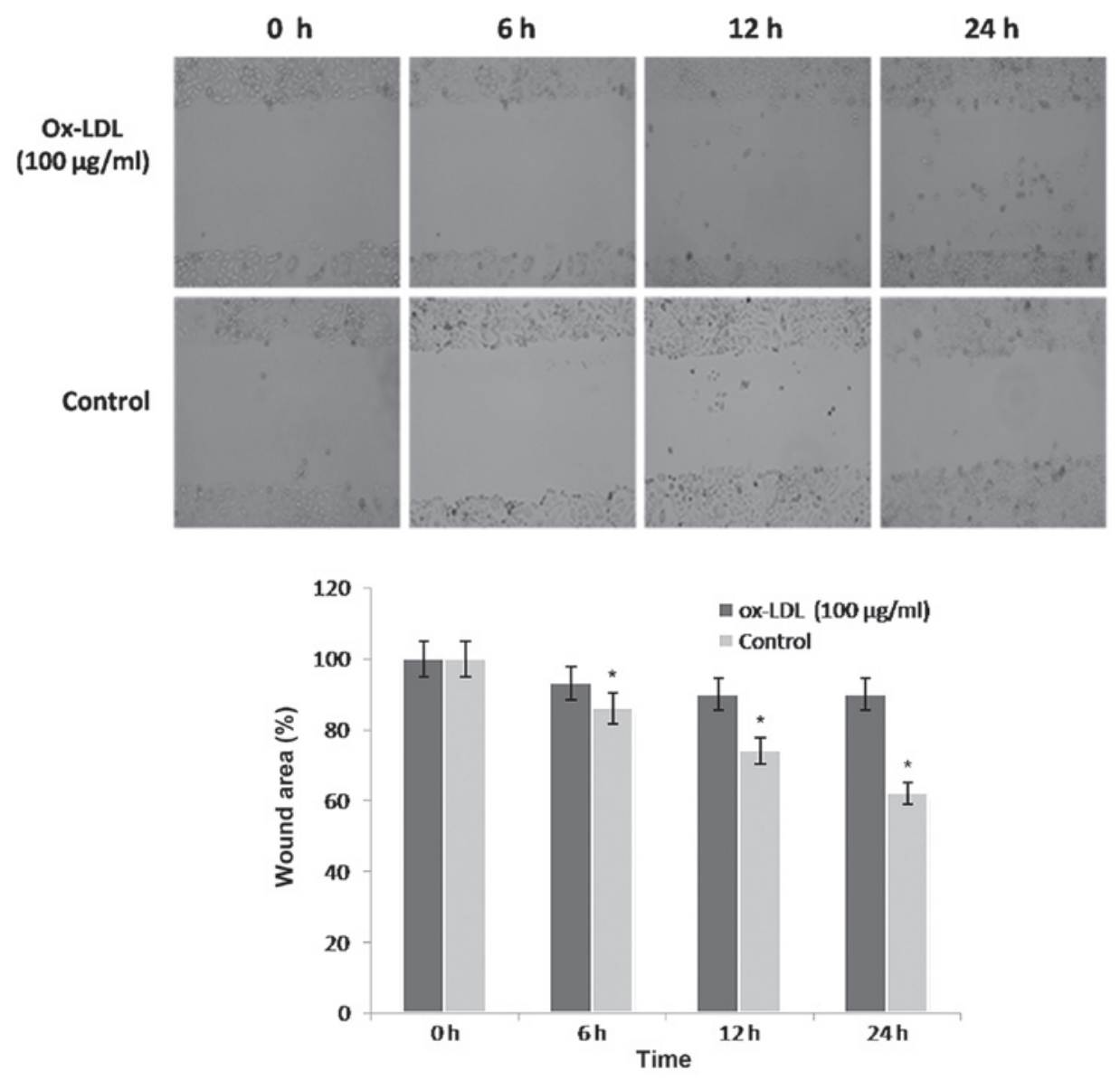

Figure 3. Effect of ox-LDL on the migration of HUVECs. HUVECs were incubated with $100 \mu \mathrm{g} / \mathrm{ml} \mathrm{ox}-\mathrm{LDL}$ for $24 \mathrm{~h}$ and cell migration was detected using wound healing assays. Ox-LDL inhibited the migration of HUVECs into the wound area. Representative images of the wound area were taken at $0,6,12$ and $24 \mathrm{~h}$ following wound induction (magnification, $\mathrm{x} 10)$. Data are expressed as the mean \pm standard deviation $(\mathrm{n}=3)$. ${ }^{*} \mathrm{P}<0.05$, vs. the control. Ox-LDL, oxidized low-density lipoprotein; HUVECs, human umbilical vein endothelial cells.

in DMEM containing $10 \mathrm{ng} / \mathrm{ml} \mathrm{VEGF}$ and/or ox-LDL $(0-100 \mu \mathrm{g} / \mathrm{ml})$ for $24 \mathrm{~h}$, after which the cells were seeded into matrigel-coated plates and the lengths of tube-like structures were measured. VEGF $(10 \mathrm{ng} / \mathrm{ml})$ induced HUVEC tube formation. Conversely, ox-LDL significantly inhibited tube formation by HUVECs in a dose-dependent manner (Fig. 4). These results suggest that ox-LDL is able to suppress HUVEC angiogenesis in vitro.

ox-LDL induces overproduction of ROS in HUVECs. The levels of ROS in HUVECs treated with ox-LDL for $24 \mathrm{~h}$ were measured using DCFH-DA staining and flow cytometry. As shown in Fig. 5, the levels of ROS were significantly increased in HUVECs following treatment with ox-LDL in a dose-dependent manner, as compared with the control $(\mathrm{P}<0.05)$. In particular, treatment with $150 \mu \mathrm{g} / \mathrm{ml}$ ox-LDL increased the levels of ROS in HUVECs by 2.18 -fold.

ox-LDL activates caspase-3 in HUVECs. The present study demonstrated that ox-LDL induced HUVEC injury, indicating a potential suppressive effect on HUVEC angiogenesis. Caspases are crucial mediators of programmed cell death (apoptosi). Among them, caspase-3 is a frequently activated death protease, catalyzing the specific cleavage of many key cellular proteins. Incubation of HUVECs with ox-LDL for
24 h significantly increased caspase-3 activity, as compared with the control $(\mathrm{P}<0.05$; Fig. 6).

$O x$-LDL regulates VEGFR2 expression at the post transcriptional level. The present study demonstrated that ox-LDL inhibited VEGF-induced angiogenesis of HUVECs. In order to investigate the underlying mechanisms, the mRNA and protein expression levels of VEGFR2 in ox-LDL-treated HUVECs were determined by RT-qPCR and western blotting, respectively. The mRNA expression levels of VEGFR2 were increased in HUVECs treated with various concentrations of ox-LDL for $24 \mathrm{~h}$ or with $100 \mu \mathrm{g} / \mathrm{ml}$ ox-LDL for various durations; however, the difference was not significant, as compared with the control ( $\mathrm{P}>0.05$; Fig. 7). Conversely, the protein expression of VEGFR was markedly decreased in HUVECs treated with ox-LDL, as compared with the control (Fig. 8). These results suggest that ox-LDL regulates VEGFR2 expression at the protein, but not the mRNA level.

\section{Discussion}

Epidemiological studies have examined the incidence of AS being $79.9 \%$ in Chinese people $>60$ years old. AS is serious but is not yet a global health emergency. Ox-LDL-induced vascular endothelial damage has been demonstrated to be a 


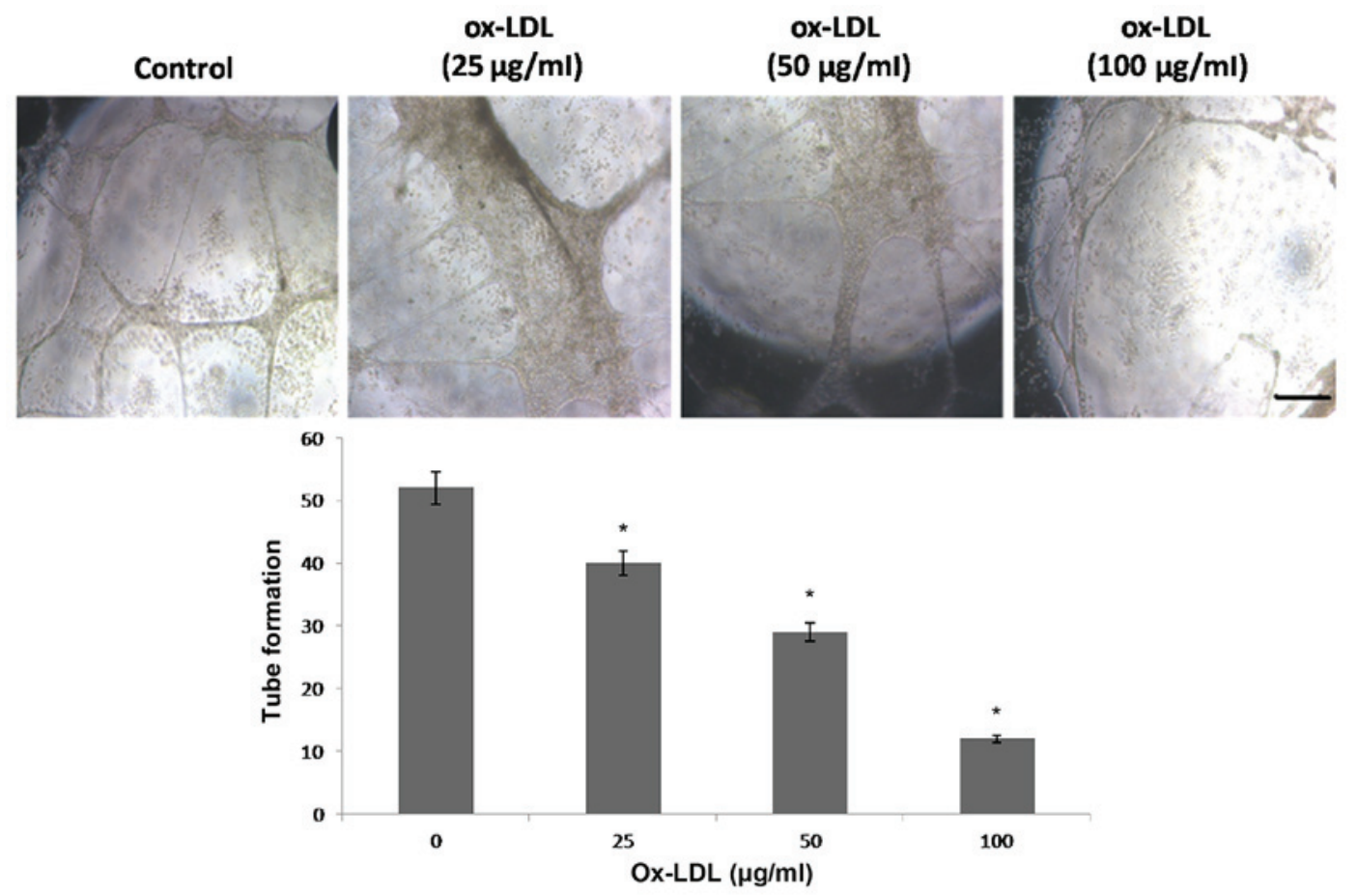

Figure 4. Effect of ox-LDL on tube formation by HUVECs. HUVECs were incubated with $10 \mathrm{ng} / \mathrm{ml}$ vascular endothelial growth factor or $0,25,50$ or $100 \mu \mathrm{g} / \mathrm{ml}$ ox-LDL for $24 \mathrm{~h}$ and angiogenesis was assessed by tube formation assays. Representative microphotographs are shown for three different doses (scale bars, $200 \mu \mathrm{m}$ ). Data are presented as the mean \pm standard deviation. ${ }^{*} \mathrm{P}<0.05$ vs. the control. Ox-LDL, oxidized low-density lipoprotein; HUVECs, human umbilical vein endothelial cells.

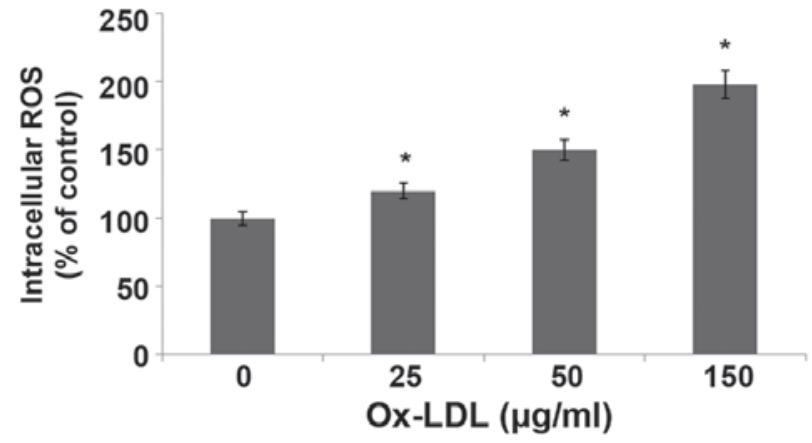

Figure 5. Effect of ox-LDL on HUVEC ROS production. HUVECs were treated with $0,25,50$ or $150 \mu \mathrm{g} / \mathrm{ml}$ ox-LDL for $24 \mathrm{~h}$, after which the levels of ROS were detected by DCFH-DA assays. Ox-LDL increased ROS production in HUVECs in a dose-dependent manner. Data are presented as the mean \pm standard deviation. "P $<0.05$, vs. the control $(0 \mu \mathrm{g} / \mathrm{ml} ; \mathrm{n}=3)$. Ox-LDL, oxidized low-density lipoprotein; ROS, reactive oxygen species; HUVECs, human umbilical vein endothelial cells.

driving force in the initiation and development of AS (20). A key therapeutic strategy for AS is the promotion of angiogenesis. Previous studies have used various strategies to induce angiogenesis, including the delivery of VEGF (21), viral vectors $(22-24)$ or plasmids $(25,26)$; however, few have shown success, which may be due to the fact that the molecular mechanisms underlying angiogenesis are largely unknown. Using proliferation, migration and tube formation assays, the present study demonstrated that ox-LDL impaired angiogenesis by HUVECs in vitro. Previous studies have associated hypercholesterolemia with impaired angiogenesis, and hypercholesterolemia has been shown to enhance oxidative

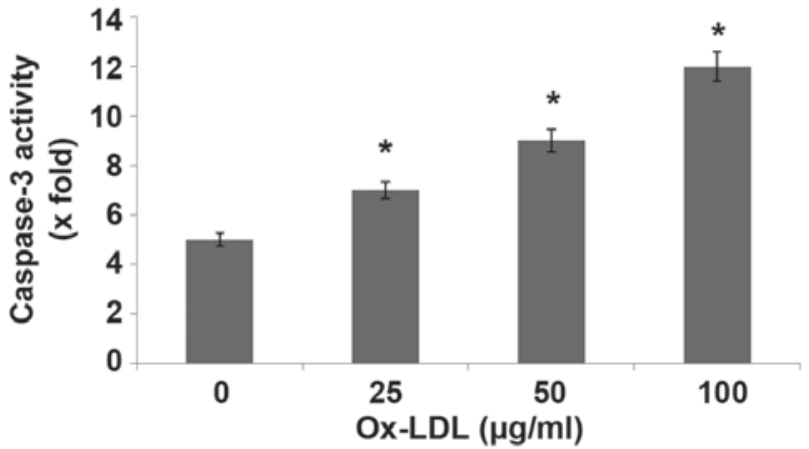

Figure 6. Effect of ox-LDL on the activity of caspase-3 in HUVECs. HUVECs were treated with $0,25,50$ or $100 \mu \mathrm{g} / \mathrm{ml}$ ox-LDL for $24 \mathrm{~h}$, after which caspase- 3 activity was assessed using commercially available kits. Ox-LDL increased caspase-3 activity in HUVECs in a dose-dependent manner. Data are presented as the mean \pm standard deviation. ${ }^{*} \mathrm{P}<0.05$, vs. the control $(0 \mu \mathrm{g} / \mathrm{ml} ; \mathrm{n}=3)$. Ox-LDL, oxidized low-density lipoprotein; HUVECs, human umbilical vein endothelial cells.

stress resulting in impaired inflammation in vivo (27-30). In the present study, ox-LDL impaired the ability of HUVECs to undergo angiogenesis by decreasing the viability and migratory and tube-forming abilities of the cells. Therefore, the present study provides novel insights into the effects of hypercholesterolemia on angiogenesis.

In the present study, ox-LDL exposure increased ROS production and caspase- 3 activity in HUVECs. In addition, ox-LDL was observed to induce the apoptosis of HUVECs. As an executioner caspase, caspase- 3 exhibits negligible activity until it is cleaved by an initiator caspase following induction of cell apoptotic events. Therefore, under normal 


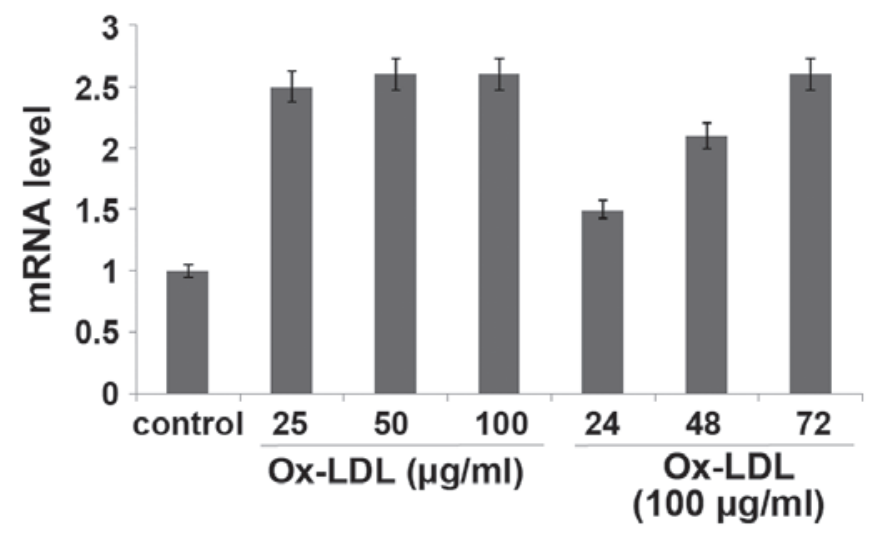

Figure 7. Effect of ox-LDL on the mRNA expression levels of VEGFR2 in HUVECs. HUVECs were treated with various concentrations of ox-LDL (25-100 $\mu \mathrm{g} / \mathrm{ml})$ or $100 \mu \mathrm{g} / \mathrm{ml}$ ox-LDL for various durations $(24-72 \mathrm{~h})$. The mRNA expression levels of VEGFR2 in HUVECs were determined by reverse transcription-quantitative polymerase chain reaction. Ox-LDL did not significantly alter the mRNA expression levels of VEGFR2 in HUVECs, as compared with the control. Ox-LDL, oxidized low-density lipoprotein HUVECs, human umbilical vein endothelial cells; VEGFR2, vascular endothelial growth factor receptor 2 .

conditions, healthy cells express full length, inactive caspase-3. As is shown in the present study, exposure of HUVECs to ox-LDL increased caspase-3 activity, thus suggesting that the rate of apoptosis was increased. These results support the hypothesis that ox-LDL is able to induce the apoptosis of HUVECs. This is significant since atherosclerosis has previously been associated with progressive endothelial cell loss (31). Therefore, the present study provides a potential mechanism by which ox-LDL exposure may enhance oxidative injury, in particular via induction of ROS production and activation of caspase-3.

Increasingly, it has been suggested that VEGFR2 drives the angiogenic response. VEGFR2 abundance and activation of the downstream signaling pathway in endothelial cells has been reported to be decreased under hypoxic conditions, such as those encountered in coronary heart disease, peripheral occlusive artery disease and ischemic stroke; and this was consistent with the results of the present study. In addition, previous studies demonstrated that ox-LDL impaired endothelial cell proliferation and migration via decreasing bFGF expression (32) and activating NO synthase/Akt signaling pathway (33). Furthermore, it has previously been shown that ox-LDL exposure decreased the expression of VEGFR1 in human macrophages (34), and internalized, ubiquinated and proteolytically degraded forms of VEGFR1 have been detected following ox-LDL exposure. However, whether ox-LDL affects the role of VEGFR2 in the angiogenic response pathway has yet to be elucidated.

The ox-LDL-mediated increase in oxidative stress-induced damage of HUVECs is suspected to underlie the pathogenesis of AS. The present study aimed to investigate the effects of ox-LDL on HUVEC apoptosis and the underlying mechanisms. Using endothelial proliferation and tube formation assays, the present study provided new evidence that ox-LDL exposure markedly affected HUVEC angiogenesis. The western blotting data confirmed that VEGFR2 was degraded

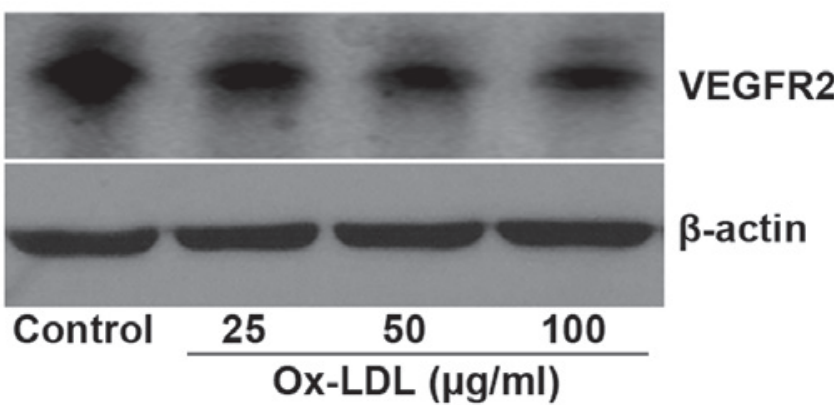

Figure 8. Effect of ox-LDL on the protein expression of VEGFR2 in HUVECs. HUVECs were treated with 25,50 or $100 \mu \mathrm{g} / \mathrm{ml}$ ox-LDL for $72 \mathrm{~h}$, after which the protein expression levels of VEGFR2 were analyzed by western blotting. $\beta$-actin served as a housekeeping protein. Ox-LDL decreased the protein expression levels of VEGFR2 in HUVECs. Ox-LDL, oxidized low-density lipoprotein; VEGFR2, vascular endothelial growth factor receptor 2; HUVECs, human umbilical vein endothelial cells.

following ox-LDL exposure, and this decrease in VEGFR2 expression may have inhibited angiogenesis by limiting the activation of signaling pathways downstream of VEGFR2. The results demonstrated that VEGFR2 receptor function was significantly affected following ox-LDL exposure.

A limitation of the present study was that only the in vitro effects of ox-LDL on HUVECs were analyzed; the dose-dependent association between ox-LDL and HUVEC response may be more complex in vivo. Further studies are required to assess the effect of ox-LDL on vessel formation in animal models, and to develop therapeutic strategies for repairing angiogenesis under hypoxic conditions.

In conclusion, the present study aimed to investigate the molecular mechanisms underlying the involvement of VEGFR2 in the regulation of oxidative stress and HUVEC injury in AS. The results of the present study suggested that ox-LDL was able to alter endothelial cell survival and function, and that downregulation of VEGFR2 expression may underlie the development of AS.

\section{Acknowledgements}

The present study was supported by grants from the Natural Science Foundation of China (no. 81401870) and the Shanghai Municipal Science and Technology Commission (no. 13ZR1459000).

\section{References}

1. Mannarino E and Pirro M: Molecular biology of atherosclerosis. Clin Cases Miner Bone Metab 5: 57-62, 2008.

2. Mitra S, Deshmukh A, Sachdeva R, Lu J and Mehta JL: Oxidized low-density lipoprotein and atherosclerosis implications in antioxidant therapy. Am J Med Sci 342: 135-142, 2011.

3. Kolluru GK1, Bir SC, Kevil CG: Endothelial dysfunction and diabetes: effects on angiogenesis, vascular remodeling, and wound healing. Int J Vasc Med: Feb 12, 2012 (Epub ahead of print) doi: 10.1155/2012/918267.

4. Mathieu P, Pibarot P and Després JP: Metabolic syndrome: The danger signal in atherosclerosis. Vasc Health Risk Manag 2: 285-302, 2006.

5. Chen CH, Jiang W, Via DP, Luo S, Li TR, Lee YT and Henry PD: Oxidized low-density lipoproteins inhibit endothelial cell proliferation by suppressing basic fibroblast growth factor expression. Circulation 101: 171-177, 2000. 
6. Inoue M, Itoh H, Tanaka T, Chun TH, Doi K, Fukunaga Y, Sawada N, Yamshita J, Masatsugu K, Saito T, et al: Oxidized LDL regulates vascular endothelial growth factor expression in human macrophages and endothelial cells through activation of peroxisome proliferator-activated receptor-gamma. Arterioscler Thromb Vasc Biol 21: 560-566, 2001.

7. Kuzuya M, Ramos MA, Kanda S, Koike T, Asai T, Maeda K, Shitara K, Shibuya M and Iguchi A: VEGF protects against oxidized LDL toxicity to endothelial cells by an intracellular glutathione-dependent mechanism through the KDR receptor. Arterioscler Thromb Vasc Biol 21: 765-770, 2001.

8. Jovinge S, Ares MP, Kallin B and Nilsson J: Human monocytes/macrophages release TNF-alpha in response to Ox-LDL. Arterioscler Thromb Vasc Biol 16: 1573-1579, 1996.

9. Erl W, Weber PC and Weber C: Monocytic cell adhesion to endothelial cells stimulated by oxidized low density lipoprotein is mediated by distinct endothelial ligands. Atherosclerosis 136 : 297-303, 1998

10. Antoniades C, Demosthenous M, Tousoulis D, Antonopoulos AS, Vlachopoulos C, Toutouza M, Marinou K, Bakogiannis C, Mavragani K, Lazaros G, et al: Role of asymmetrical dimethylarginine in inflammation-induced endothelial dysfunction in human atherosclerosis. Hypertension 58: 93-98, 2011.

11. Thorin-Trescases N, Voghel G, Gendron ME, Krummen S, Farhat N, Drouin A, Perrault LP and Thorin E: Pathological aging of the vascular endothelium: Are endothelial progenitor cells the sentinels of the cardiovascular system? Can J Cardiol 21: 1019-1024, 2005 .

12. Chen YH, Lin SJ, Chen YL, Liu PL and Chen JW: Anti-inflammatory effects of different drugs/agents with antioxidant property on endothelial expression of adhesion molecules. Cardiovasc Hematol Disord Drug Targets 6: 279-304, 2006.

13. Zhang J, Alcaide P, Liu L, Sun J, He A, Luscinskas FW and Shi GP: Regulation of endothelial cell adhesion molecule expression by mast cells, macrophages, and neutrophils. PLoS One 6: e14525, 2011

14. Chi Z and Melendez AJ: Role of cell adhesion molecules and immune-cell migration in the initiation, onset and development of atherosclerosis. Cell Adh Migr 1: 171-175, 2007.

15. Koch S and Claesson-Welsh L: Signal transduction by vascular endothelial growth factor receptors. Cold Spring Harb Perspect Med 2: a006502, 2012.

16. Goel HL and Mercurio AM: VEGF targets the tumour cell. Nat Rev Cancer 13: 871-882, 2013.

17. Carmeliet P and Jain RK: Molecular mechanisms and clinical applications of angiogenesis. Nature 473: 298-307, 2011.

18. Gerhardt H, Golding M, Fruttiger M, Ruhrberg C, Lundkvist A, Abramsson A, Jeltsch M, Mitchell C, Alitalo K, Shima D and Betsholtz C: VEGF guides angiogenic sprouting utilizing endothelial tip cell filopodia. J Cell Biol 161: 1163-1177, 2003.

19. Chen B, Zhao J, Zhang S, Wu W and Qi R: Aspirin inhibits the production of reactive oxygen species by downregulating Nox4 and inducible nitric oxide synthase in human endothelial cells exposed to oxidized low-density lipoprotein. J Cardiovasc Pharmacol 59: 405-412, 2012.

20. Pirillo A, Norata GD and Catapano AL: LOX-1, OxLDL, and atherosclerosis. Mediators Inflamm. Jul 10, 2013. (Epub ahead of print) doi: 10.1155/2013/152786.

21. Henry TD, Annex BH, McKendall GR, Azrin MA, Lopez JJ, Giordano FJ, Shah PK, Willerson JT, Benza RL, Berman DS, et al; VIVA Investigators: The VIVA trial: Vascular endothelial growth factor in Ischemia for Vascular Angiogenesis. Circulation 107: 1359-1365, 2003.

22. Mäkinen K, Manninen H, Hedman M, Matsi P, Mussalo H, Alhava E and Ylä-Herttuala S: Increased vascularity detected by digital subtraction angiography after VEGF gene transfer to human lower limb artery: A randomized, placebo-controlled, double-blinded phase II study. Mol Ther 6: 127-133, 2002.
23. Hedman M, Hartikainen J, Syvänne M, Stjernvall J, Hedman A Kivelä A, Vanninen E, Mussalo H, Kauppila E, Simula S, et al: Safety and feasibility of catheter-based local intracoronary vascular endothelial growth factor gene transfer in the prevention of postangioplasty and in-stent restenosis and in the treatment of chronic myocardial ischemia: Phase II results of the Kuopio Angiogenesis Trial (KAT). Circulation 107: 2677-2683, 2003.

24. Rajagopalan S, Mohler ER III, Lederman RJ, Mendelsohn FO, Saucedo JF, Goldman CK, Blebea J, Macko J, Kessler PD, Rasmussen HS and Annex BH: Regional angiogenesis with vascular endothelial growth factor in peripheral arterial disease: A phase II randomized, double-blind, controlled study of adenoviral delivery of vascular endothelial growth factor 121 in patients with disabling intermittent claudication. Circulation 108: 1933-1938, 2003.

25. Kukuła K, Chojnowska L, Dąbrowski M, Witkowski A, Chmielak Z, Skwarek M, Kądziela J, Teresińska A, Małecki M, Janik P, et al: Intramyocardial plasmid-encoding human vascular endothelial growth factor A165/basic fibroblast growth factor therapy using percutaneous transcatheter approach in patients with refractory coronary artery disease (VIF-CAD). Am Heart J 161: 581-589, 2011.

26. Kastrup J, Jørgensen E, Rück A, Tägil K, Glogar D, Ruzyllo W, Bøtker HE, Dudek D, Drvota V, Hesse B, et al; Euroinject One Group: Direct intramyocardial plasmid vascular endothelial growth factor-A165 gene therapy in patients with stable severe angina pectoris A randomized double-blind placebo-controlled study: The Euroinject One trial. J Am Coll Cardiol 45: 982-988, 2005.

27. Duan J, Murohara T, Ikeda H, Katoh A, Shintani S, Sasaki K, Kawata H, Yamamoto N and Imaizumi T: Hypercholesterolemia inhibits angiogenesis in response to hindlimb ischemia: Nitric oxide-dependent mechanism. Circulation 102 (Suppl 3): III370-III376, 2000.

28. Matter CM, Ma L, von Lukowicz T, Meier P, Lohmann C, Zhang D, Kilic U, Hofmann E, Ha SW, Hersberger M, et al: Increased balloon-induced inflammation, proliferation, and neointima formation in apolipoprotein E (ApoE) knockout mice. Stroke 37: 2625-2632, 2006

29. Osto E, Matter CM, Kouroedov A, Malinski T, Bachschmid M, Camici GG, Kilic U, Stallmach T, Boren J, Iliceto S, et al: c-Jun $\mathrm{N}$-terminal kinase 2 deficiency protects against hypercholesterolemia-induced endothelial dysfunction and oxidative stress. Circulation 118: 2073-2080, 2008.

30. ElAli A, Doeppner TR, Zechariah A and Hermann DM: Increased blood-brain barrier permeability and brain edema after focal cerebral ischemia induced by hyperlipidemia: Role of lipid peroxidation and calpain-1/2, matrix metalloproteinase-2/9, and RhoA overactivation. Stroke 42: 3238-3244, 2011.

31. Du F, Zhou J, Gong R, Huang X, Pansuria M, Virtue A, Li X, Wang $\mathrm{H}$ and Yang XF: Endothelial progenitor cells in atherosclerosis. Front Biosci (Landmark Ed) 17: 2327-2349, 2012.

32. Chang PY, Luo S, Jiang T, Lee YT, Lu SC, Henry PD and Chen $\mathrm{CH}$ : Oxidized low-density lipoprotein downregulates endothelial basic fibroblast growth factor through a pertussis toxin-sensitive G-protein pathway: Mediator role of platelet-activating factor-like phospholipids. Circulation 104: 588-593, 2001.

33. Chavakis E, Dernbach E, Hermann C, Mondorf UF, Zeiher AM and Dimmeler S: Oxidized LDL inhibits vascular endothelial grow th factor-induced endothelial cell migration by an inhibitory effect on the Akt/endothelial nitric oxide synthase pathway. Circulation 103: 2102-2107 2001.

34. Salomonsson L, Svensson L, Pettersson S, Wiklund O and Ohlsson BG: Oxidised LDL decreases VEGFR-1 expression in human monocyte-derived macrophages. Atherosclerosis 169: 259-267, 2003. 